http://jmscr.igmpublication.org/home/ ISSN (e)-2347-176x ISSN (p) 2455-0450

crossref DOI: https://dx.doi.org/10.18535/jmscr/v10i2.31

Journal Of Medical Science And Clinical Research

\title{
A Comparative Study to Evaluate the Post Operative Analgesia Comparing Dexmedetomidine and Clonidine with Epidural Levobupivacaine for Pelvis and Lower Limb Orthopaedic Surgeries
}

\author{
Authors \\ Dr Amutha Rani $\mathbf{R}^{1 *}$, Dr Ahila $K^{2}$, Dr Manivel Ganesan ${ }^{3}$ \\ ${ }^{1}$ Professor \& HOD, Department of Anaesthesiology, Tirunelveli Medical College \\ ${ }^{2}$ Assistant Professor, Department of Anaesthesiology, Tirunelveli Medical College \\ ${ }^{3}$ Junior Resident, Department of Anaesthesiology, Tirunelveli Medical College \\ *Corresponding Author \\ Dr Amutha Rani R MD \\ Prof \& HOD, Department of Anaesthesiology, Tirunelveli Medical College
}

\begin{abstract}
Background: Alpha 2 agonists are being used as adjuvants in epidural analgesia as they lead to analgesia, anxiolysis and sedation.

Aim: This study aims to evaluate the post operative analgesic effects of epidural dexmedetomidine and clonidine with $0.125 \%$ levobupivacaine

Methods: A comparative study was done to assess the efficacy and clinical profile of two a2 adrenergic agonists - clonidine and dexmedetomidine administered epidurally in combination with intrathecal $0.125 \%$ levobupivacaine. The study was conducted for 1 year. Sixty adult patients ASA-PS Class I and II undergoing pelvis and lower limb orthopaedic surgery were randomly assigned into two groups, to receive either epidural dexmedetomidine (1 $\mu \mathrm{g} / \mathrm{kg})$ or clonidine $(2 \mu \mathrm{g} / \mathrm{kg})$ with $0.125 \%$ isobaric levobupivacaine.

Results: Dexmedetomidine provided a prolonged analgesia, as evidenced by the distribution of VAS scores and requirement rescue analgesic among two groups.

Keywords: Epidural analgesia, 0.125\%Levobupivacaine, Dexmedetomidine, Clonidine.
\end{abstract}

\section{Introduction}

It has been hypothesized that epidural anaesthesia lessens the perioperative stress and works on careful result of surgical success by relieving the pain. Artistic proof has set up the safety of levobupivacaine over bupivacaine when utilized in epidural anaesthesia as the rate of different unfavourable outcome is higher with the last when compared with levobupivacaine.

As an amide local anaesthetic, the activity and pharmacodynamics of levobupivacaine are like those of bupivacaine. It applies its effects through reversible blockade of neuronal sodium channels. Myelinated nerves are obstructed through exposure at the nodes of Ranvier more promptly than unmyelinated nerves; and small nerves are impeded more effectively than large nerves. Levobupivacaine is lipid solvent and exceptionally protein bound. The PKa of levobupivacaine is like that of bupivacaine and ropivacaine; however higher than that of lignocaine. Its higher lipid-solvency makes it 
more powerful which brings about a longer duration of action.

Alpha-2 adrenergic agonists have both pain relieving and narcotic properties when utilized as an adjuvant in local sedation. They have been accounted for to work on the improved epidural sedation. The sedative and the pain relieving necessity gets diminished to a greater degree by the utilization of these two adjuvants on account of their pain relieving properties and augmentation of local anaesthetic effects as they cause hyperpolarization of nerve tissue by modifying transmembrane potential and particle conductance at locus coeruleus in the brainstem. These medications cause negligible respiratory depression when utilized as adjuvants to local sedation.

\section{Aim and Objective}

The present comparative study aims at comparing the haemodynamic, sedative and analgesia potentiating effects of epidurally administered clonidine and dexmedetomidine when combined with $0.125 \%$ Levobupivacaine epidurally in patients undergoing pelvis and lower limb orthopaedic surgeries.

\section{Materials and Methodology \\ Inclusion Criteria}

- Sixty individuals who had been admitted for pelvis\& lower limb orthopedic surgeries, in the age Group of 18 - 60 years in the ASA I and II grade were included.

\section{Exclusion Criteria}

- Known allergic patients to local anaesthetics, Clonidine \& Dexmedetomidine

- Patient refusal

- Infection at the localsite of injection

- Haematological disease

- coagulopathies

- psychiatric diseases

- second- or third-degree heart block

- renal and hepatic insufficiency
- uncontrolled diabetes and hypertension

- history of drug abuse

\section{Study Design}

Patients were split into two groups, 30 patients in each of Clonidine group and Dexmedetomidine group randomly.

\section{Study Method}

Under stringent aseptic precautions affected person in sitting position, epidural space displaying utilizing 18G Tuohy needle with loss of resistance method at L2 L3 inter vertebral space. Once the epidural room was revealed, epidural catheter was placed and four $\mathrm{cm}$ length of catheter placed within the area. A test dose serving of $3 \mathrm{ml}$ of $1.5 \%$ lignocaine with $15 \mu \mathrm{g}$ adrenaline was provided. Right after excluding inadvertent subarachnoid or maybe intravascular positioning of catheter, Sub-arachnoid block was carried out at L3 - L4 Intervertebral space by using 23G Quinckebabcock's spinal needle. $3 \mathrm{ml}$ of Inj. Bupivacaine $0.5 \%$ (heavy) was injected into the subarachnoid space. Patient positioned in supine position carefully. If the sensory blockade reached T10 level, surgery was commenced. Intra operatively pulse rate, respiratory rate, blood pressure, saturation $(\mathrm{SpO} 2)$, urine output had been monitored. Following the surgery, patient was shifted to ICU for post operative pain control. In the ICU, post operative epidural analgesia was provided in the serving of Inj. Levobupivacaine $0.125 \% 8 \mathrm{ml}$ volume with dexmedetomidine $1 \mu \mathrm{g}$ $/ \mathrm{ml}$ in one group and other group received inj. Levobupivacaine $0.125 \% \quad 8 \mathrm{ml}$ volume with clonidine $2 \mathrm{mcg} / \mathrm{ml}$ of epidural analgesic supplementation and patients were monitored.

\section{Variables Observed}

1) Time to achieve T10 sector sensory block after time of subarachnoid block to loss of pin prick sensation at $\mathrm{T} 10$

2) 2 segment regression time in subarachnoid block (in minutes) - time period to regress sensation to pin prick 2 sections from the 
top degree of blockade.

3) Time to need very first epidural top up since time of subarachnoid block performed (when VAS score > 5)

- Totalnumber of epidural supplementations

- Time interval between each epidural analgesic supplementation

- Side effects like dizziness, headache, nausea, vomiting, ataxia, bradycardia

\section{Visual analogue pain score}

Individuals have been asked to draw the effort on the ten point visible analogue scale of Pain based on the intensity of pain. It was noticed each hour

0-10 Numeric Pain Rating Scale

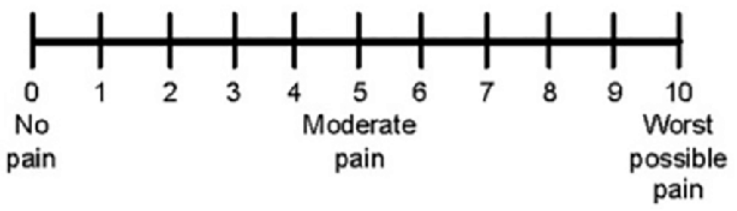

\section{Observation and Results}

\section{Age of the Study Population}

More individuals from both the clonidine and dexmedetomidine group falls under age group of 30-39 with $40 \%$ each respectively.

\begin{tabular}{|l|c|c|c|c|c|}
\hline Age Group & \multicolumn{2}{|c|}{ Clonidine } & \multicolumn{2}{|c|}{ Dexmeditomedine } & \multirow{2}{*}{ Grand Total } \\
\cline { 2 - 5 } Parameters & Frequency & Percentage & Frequency & Percentage & 2 \\
\hline$<20$ & 1 & 3.33 & 1 & 3.33 & 15 \\
\hline $20-29$ & 10 & 33.33 & 5 & 16.67 & 27 \\
\hline $30-39$ & 12 & 40.00 & 15 & 50.00 & 13 \\
\hline $40-50$ & 6 & 20.00 & 7 & 23.33 & 3 \\
\hline$>50$ & 1 & 3.33 & 2 & 6.67 & 60 \\
\hline Grand Total & $\mathbf{3 0}$ & 100.00 & $\mathbf{3 0}$ & 100.00 & \\
\hline
\end{tabular}

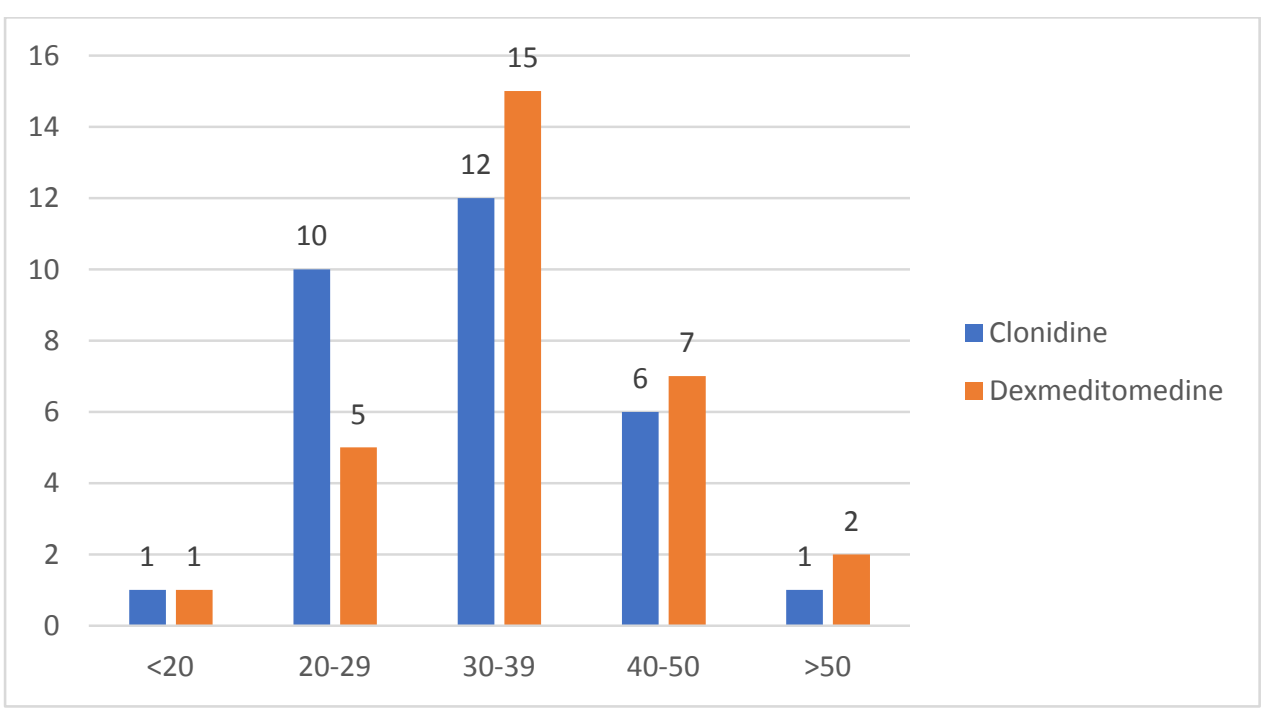

\section{Sex of the Study Population}

Both groups had more males as the participants for the study.

\begin{tabular}{|l|c|c|c|c|c|}
\hline \multirow{3}{*}{ Sex } & \multicolumn{2}{|c|}{ Clonidine } & \multicolumn{2}{c|}{ Dexmeditomedine } & \multirow{2}{*}{$\begin{array}{c}\text { Grand } \\
\text { Total }\end{array}$} \\
\cline { 2 - 5 } Parameters & Frequency & Percentage & Frequency & Percentage & 38 \\
\hline Male & 18 & 60.00 & 20 & 66.67 & 32 \\
\hline Female & 12 & 40.00 & 10 & 33.33 & 60 \\
\hline Grand Total & 30 & 100.00 & 30 & 100.00 & 60 \\
\hline
\end{tabular}




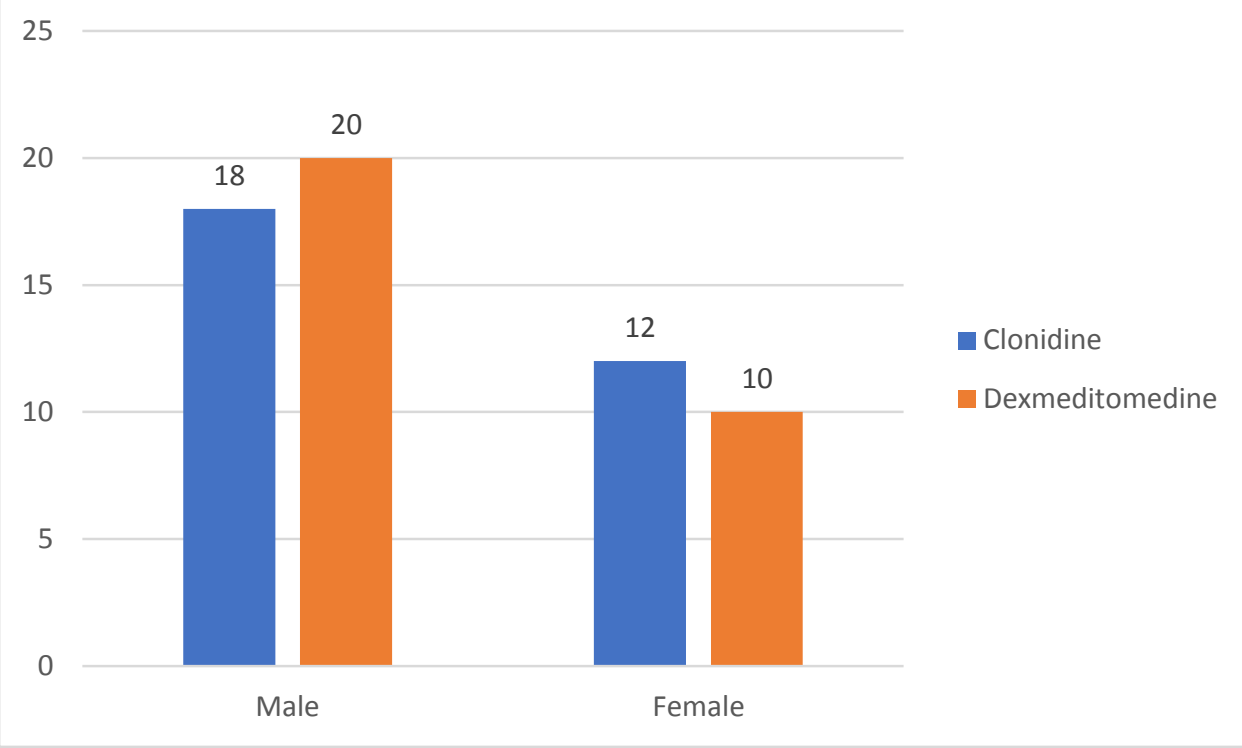

\section{BMI of the study groups:}

Both the groups had individuals being normal in weight, $60 \%$ among the clonidine group while 53.33\% among dexmedetomidine group.

\begin{tabular}{|l|c|c|c|c|c|}
\hline \multirow{2}{*}{ BMI } & \multicolumn{2}{|c|}{ Clonidine } & \multicolumn{2}{c|}{ Dexmeditomedine } & Grand \\
\cline { 2 - 5 } Parameters & Frequency & Percentage & Frequency & Percentage & Total \\
\hline Underweight & 1 & 3.33 & 0 & 0.00 & 1 \\
\hline Normal & 18 & 60.00 & 16 & 53.33 & 34 \\
\hline Overweight & 7 & 23.33 & 10 & 33.33 & 17 \\
\hline Obese & 4 & 13.33 & 4 & 13.33 & 8 \\
\hline Grand Total & 30 & 100.00 & 30 & 100.00 & 60 \\
\hline
\end{tabular}

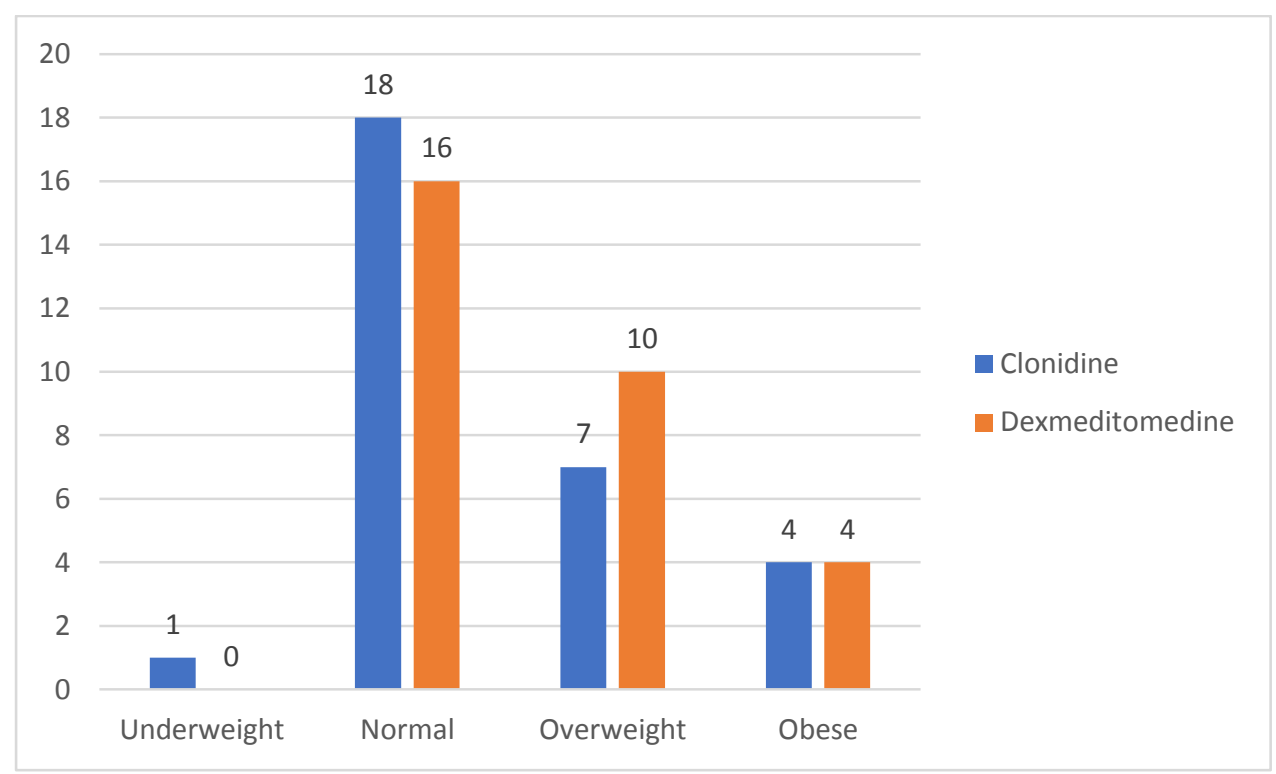

Mean BMI of the clonidine and dexmedetomidine groups are $23.93 \& 24.85$ mean values respectively.

\begin{tabular}{|l|c|c|c|}
\hline BMI & Mean & Standard Deviation & p value \\
\hline Clonidine & 23.9367 & 4.2172 & \\
\cline { 1 - 3 } Dexmeditomedine & 24.8512 & 4.4333 & 0.4163 \\
\hline
\end{tabular}




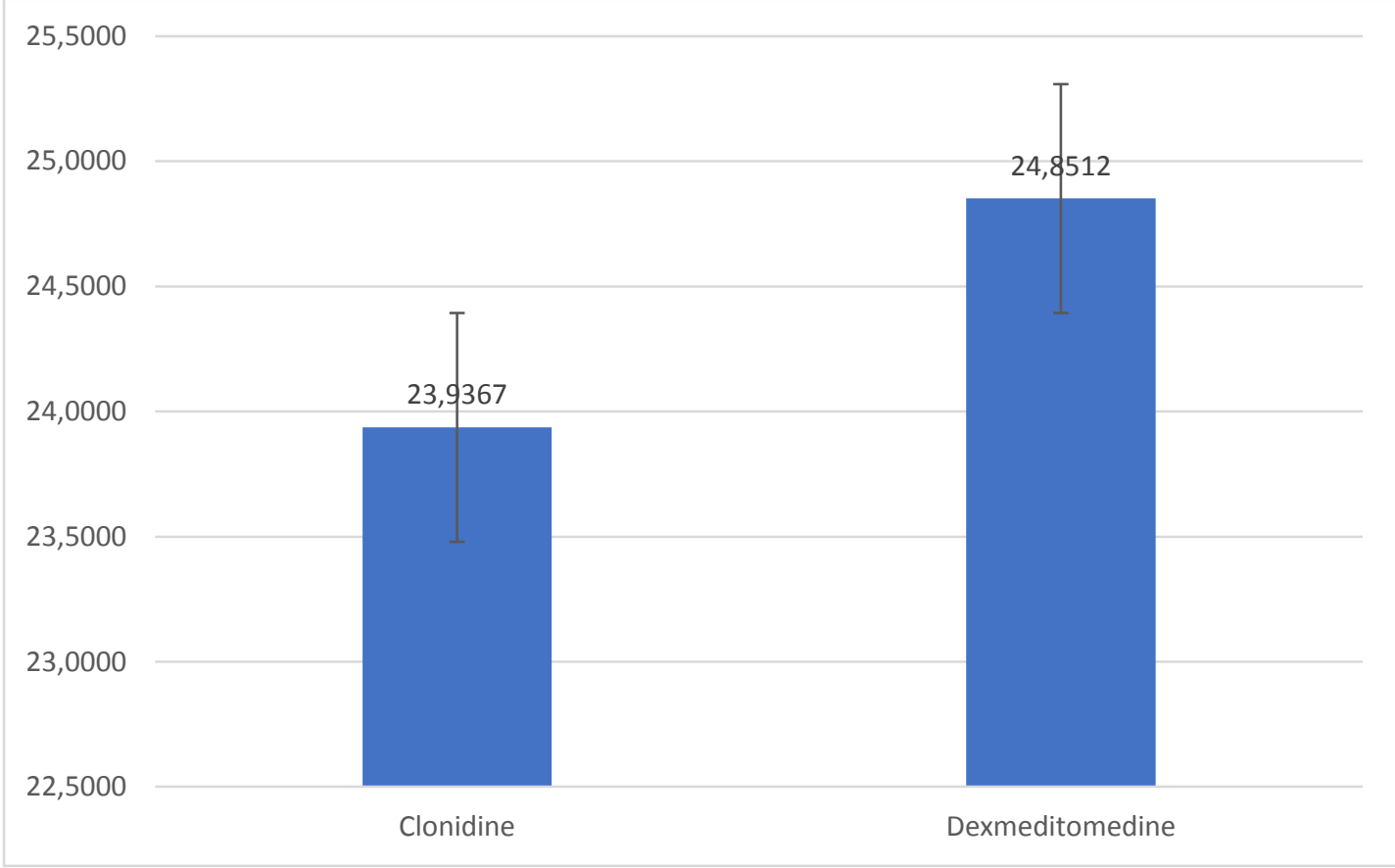

\section{Onset of analgesia}

Onset of analgesia is earlier for dexmedetomidine group with mean of 6.9 while clonidine has 7.5 and it seemed to be statistically significant.[1,7]

\begin{tabular}{|l|c|c|c|}
\hline Onset of analgesia & Mean & Standard Deviation & $\mathrm{p}$ value \\
\hline Clonidine & 7.5233 & 1.2781 & \\
\hline Dexmeditomedine & 6.9267 & 0.8952 & 0.0406 \\
\hline
\end{tabular}

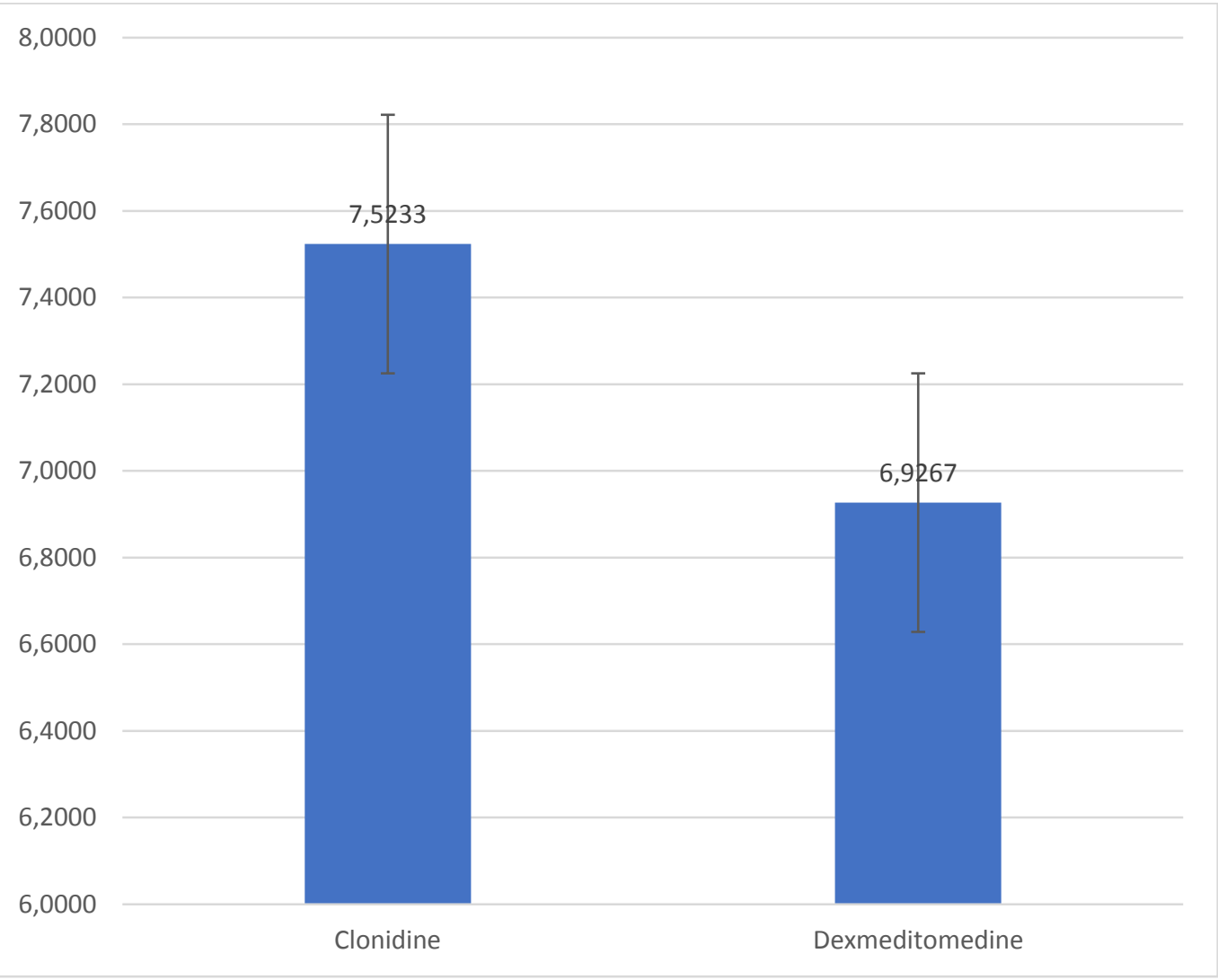




\section{JMSCR Vol||10||Issue||02||Page 176-187||February}

Time of peak onset of analgesia

The peak onset of analgesia is found to earlier in the dexmedetomidine group (mean of 10.85) than the clonidine group. ${ }^{[2,5]}$

\begin{tabular}{|l|c|c|c|}
\hline \multicolumn{1}{|l|}{ Time of peak onset of analgesia } & \multicolumn{3}{l|}{} \\
\cline { 1 - 3 } & Mean & Standard Deviation & \multirow{2}{*}{0.0000} \\
\hline Clonidine & 13.4400 & 1.0944 & 0.000 \\
\hline Dexmeditomedine & 10.8533 & 1.3472 & \\
\hline
\end{tabular}

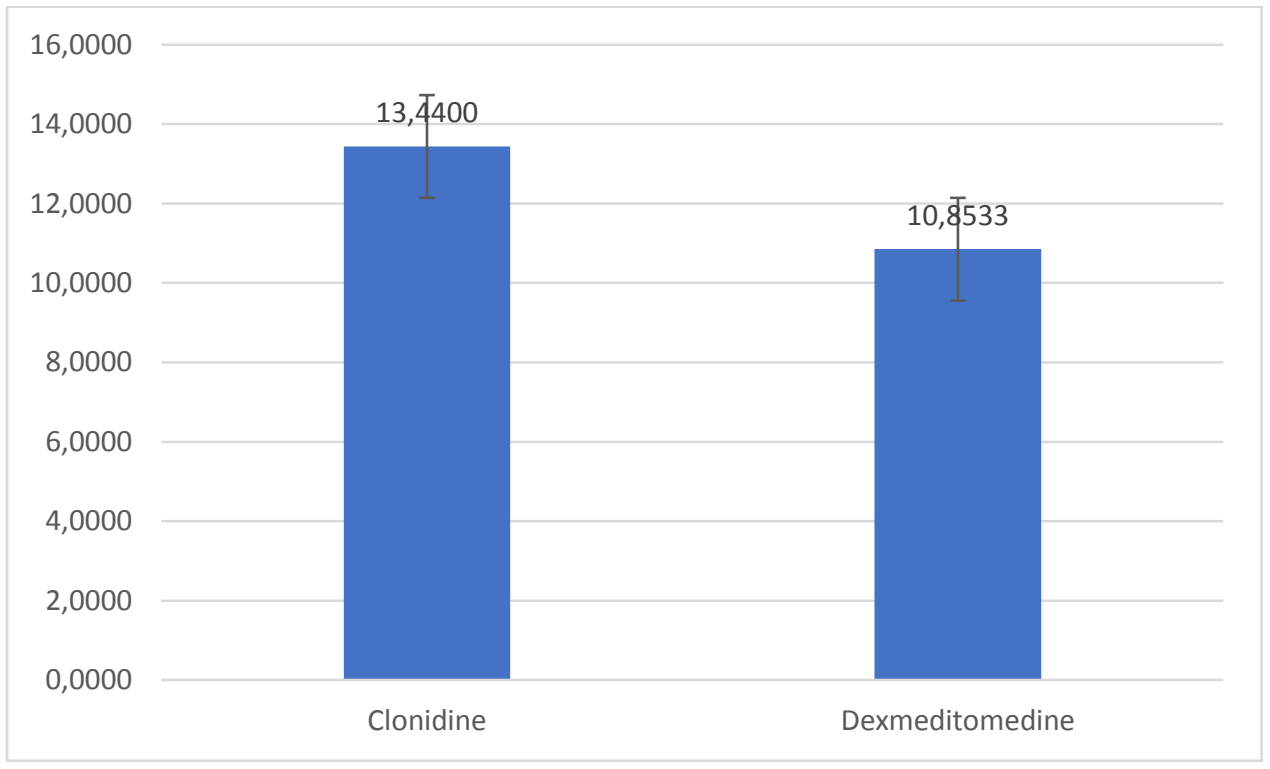

\section{Duration of analgesia}

The average time duration of analgesic effect is more for the dexmedgroup (mean value of 345.44 minutes) compared with the (mean value of 303.39 minutes) in the clonidine group. ${ }^{\text {[6] }}$

\begin{tabular}{|l|c|c|c|}
\hline Duration of analgesia & \multicolumn{3}{|c|}{$\mathrm{p}$ Malue } \\
\hline & Mean & Standard Deviation & \multirow{2}{*}{0.0000} \\
\hline Clonidine & 303.3933 & 19.3684 & \multirow{2}{*}{0.5832} \\
\cline { 1 - 3 }
\end{tabular}

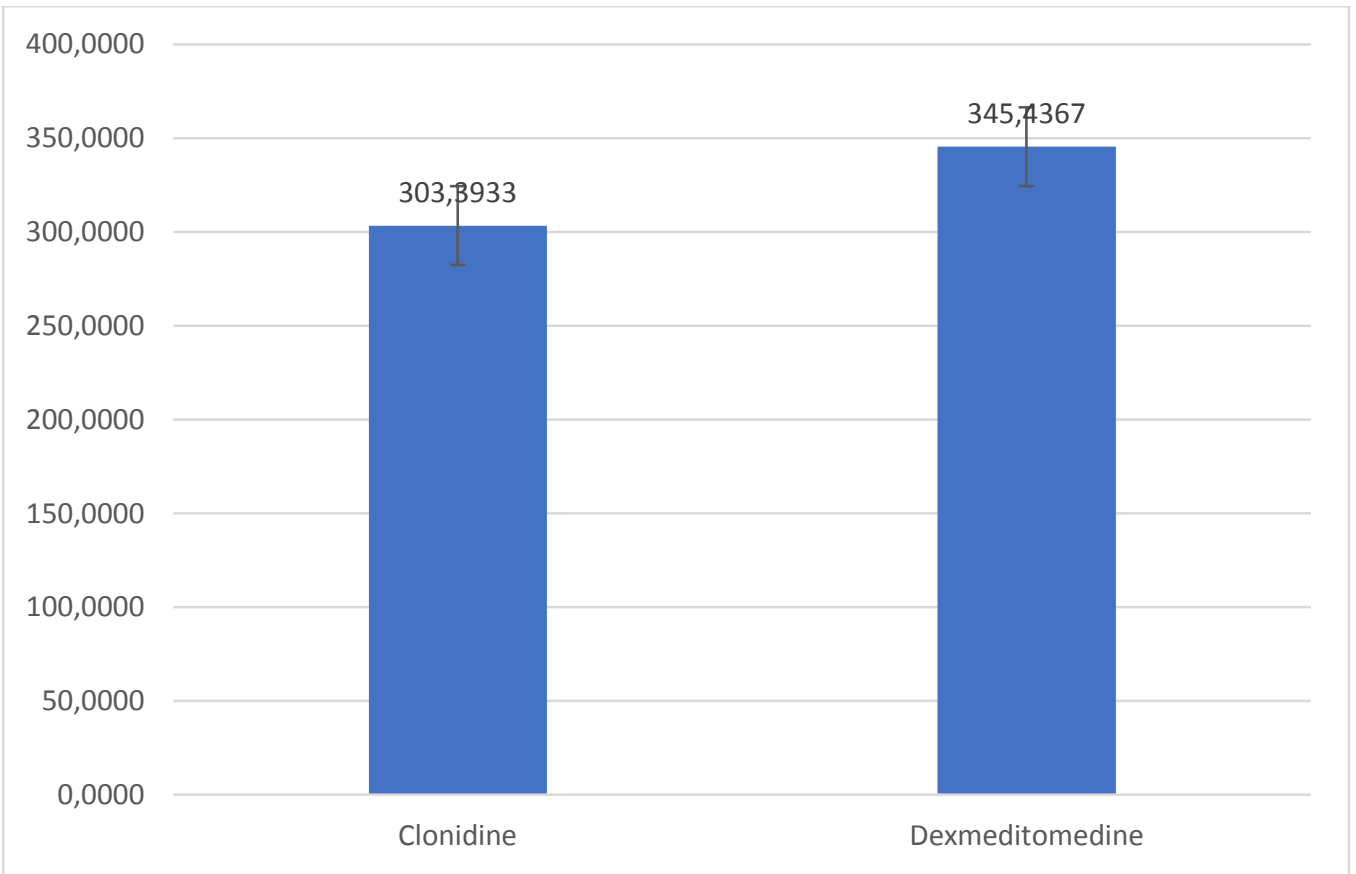


Mean heart rate during the procedure:

Initially around the 5 minute mark mean heart rate seems to go past 100 for both the groups.

\begin{tabular}{|c|c|c|c|c|c|}
\hline \multicolumn{6}{|l|}{ Heart Rate } \\
\hline \multirow[b]{2}{*}{ Parameters } & \multicolumn{2}{|c|}{ Clonidine } & \multicolumn{2}{|c|}{ Dexmeditomedine } & \multirow[b]{2}{*}{$\mathrm{p}$ value } \\
\hline & Mean & Standard Deviation & Mean & Standard Deviation & \\
\hline $0 \min$ & 89.7667 & 5.8996 & 90.6000 & 6.5422 & 0.6063 \\
\hline $1 \mathrm{~min}$ & 89.6667 & 5.2479 & 88.5667 & 6.3500 & 0.4675 \\
\hline $5 \mathrm{~min}$ & 104.8667 & 3.1811 & 105.2333 & 2.8850 & 0.6418 \\
\hline $15 \min$ & 88.2000 & 5.8333 & 89.9667 & 6.1671 & 0.2590 \\
\hline $30 \mathrm{~min}$ & 90.5667 & 5.7994 & 92.0667 & 6.3078 & 0.3416 \\
\hline $60 \mathrm{~min}$ & 91.0000 & 6.6332 & 90.9333 & 6.3023 & 0.9683 \\
\hline $90 \mathrm{~min}$ & 91.2333 & 5.7457 & 90.2000 & 6.0992 & 0.5021 \\
\hline
\end{tabular}

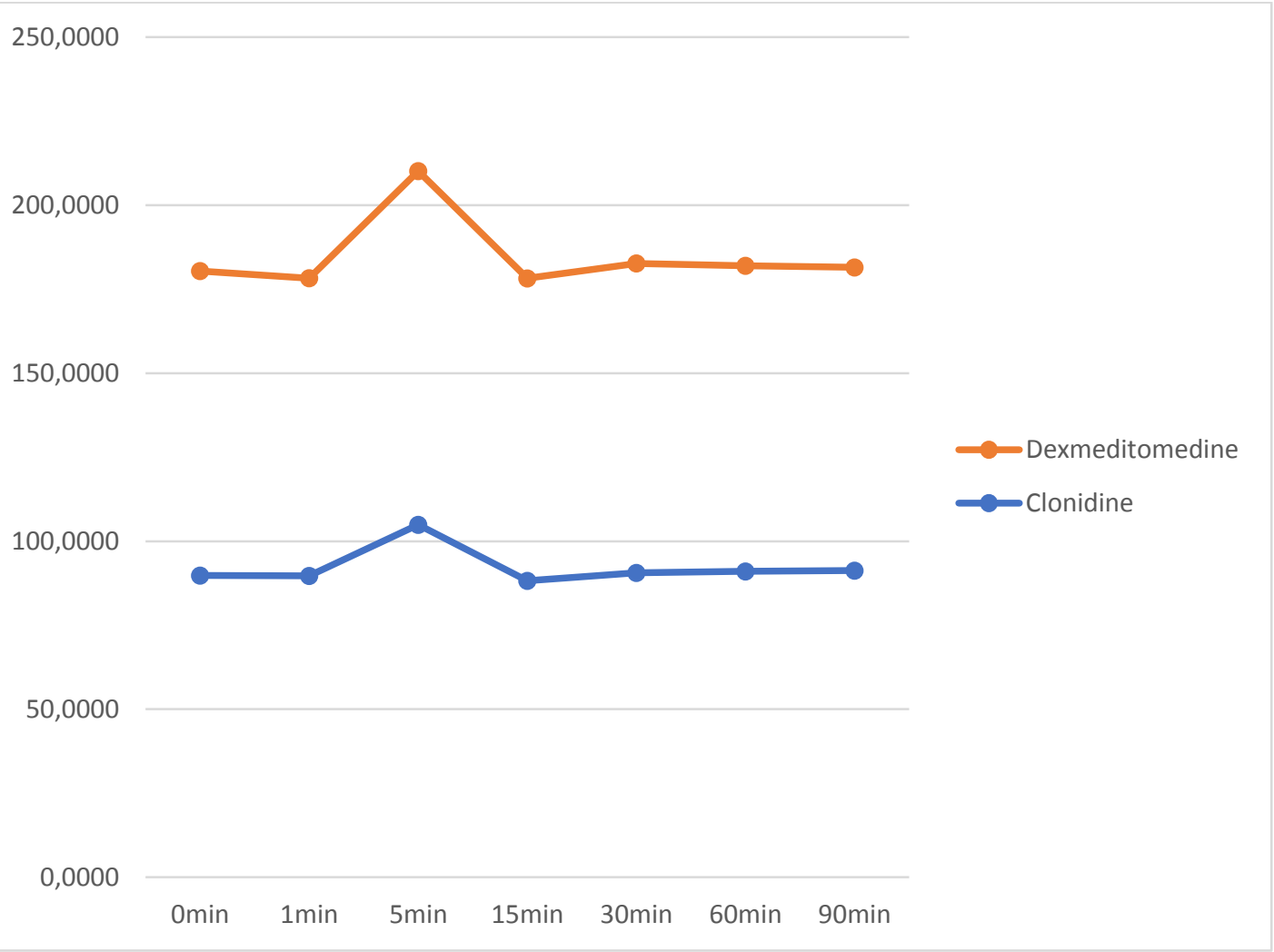

\section{Mean Systolic blood pressure during the procedure:}

Higher blood pressure readings at the earlier phases and lower values as the effect gets more enhanced is the trend seen in both the groups. $[3,4]$

\begin{tabular}{|c|c|c|c|c|c|}
\hline \multicolumn{6}{|l|}{ SBP } \\
\hline \multirow[b]{2}{*}{ Parameters } & \multicolumn{2}{|c|}{ Clonidine } & \multicolumn{2}{|c|}{ Dexmeditomedine } & \multirow[b]{2}{*}{$\mathrm{p}$ value } \\
\hline & Mean & Standard Deviation & Mean & Standard Deviation & \\
\hline $0 \min$ & 120.4000 & 5.5124 & 118.0000 & 5.9364 & 0.1101 \\
\hline 1 min & 114.6667 & 2.8808 & 115.4333 & 2.8969 & 0.3083 \\
\hline $5 \mathrm{~min}$ & 94.6000 & 3.0126 & 94.9000 & 2.9048 & 0.6960 \\
\hline $15 \min$ & 104.6000 & 3.1028 & 105.4000 & 3.1250 & 0.3239 \\
\hline 30min & 108.1333 & 5.8353 & 110.8333 & 5.2920 & 0.0655 \\
\hline $60 \mathrm{~min}$ & 113.8667 & 2.6226 & 113.9667 & 2.7478 & 0.8858 \\
\hline $90 \mathrm{~min}$ & 109.2667 & 7.0854 & 109.2000 & 6.5464 & 0.9699 \\
\hline
\end{tabular}




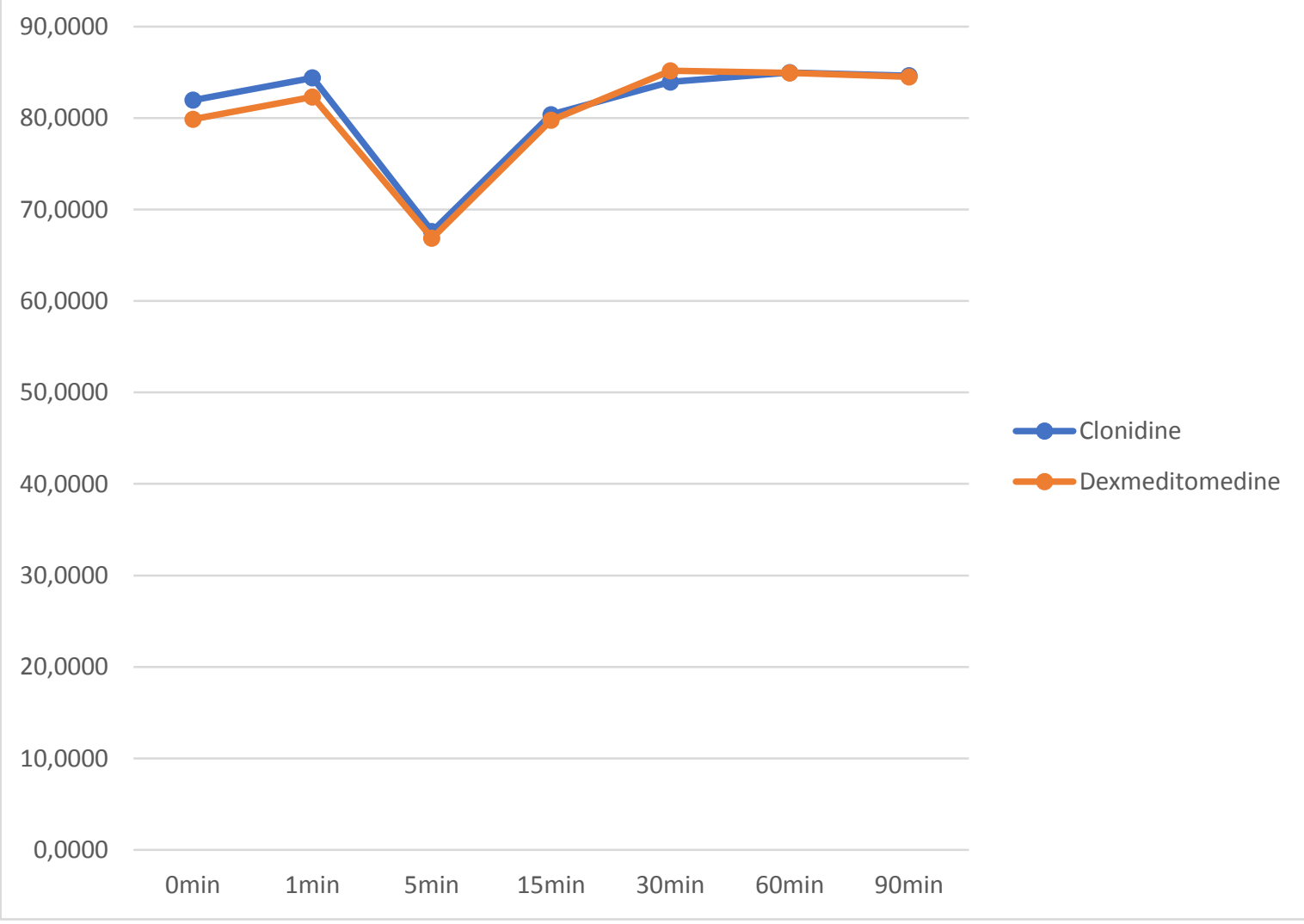

\section{Mean diastolic blood pressure during the procedure:}

Higher blood pressure readings at the earlier phases and lower values later in both the groups. ${ }^{[8]}$

\begin{tabular}{|c|c|c|c|c|c|}
\hline \multicolumn{6}{|l|}{ DBP } \\
\hline \multirow[b]{2}{*}{ Parameters } & \multicolumn{2}{|c|}{ Clonidine } & \multicolumn{2}{|c|}{ Dexmeditomedine } & \multirow[b]{2}{*}{$\mathrm{p}$ value } \\
\hline & Mean & Standard Deviation & Mean & Standard Deviation & \\
\hline $0 \min$ & 81.9667 & 6.1222 & 79.8667 & 5.9465 & 0.1830 \\
\hline 1 min & 84.4000 & 4.0052 & 82.3000 & 4.4268 & 0.0589 \\
\hline $5 \mathrm{~min}$ & 67.6000 & 4.6505 & 66.8667 & 4.4855 & 0.5366 \\
\hline $15 \mathrm{~min}$ & 80.3667 & 2.9300 & 79.7667 & 2.7628 & 0.4178 \\
\hline $30 \mathrm{~min}$ & 83.9333 & 3.3624 & 85.1667 & 3.4148 & 0.1640 \\
\hline $60 \mathrm{~min}$ & 84.9667 & 3.3060 & 84.9333 & 3.3521 & 0.9692 \\
\hline $90 \mathrm{~min}$ & 84.6333 & 3.2215 & 84.5000 & 2.9449 & 0.8677 \\
\hline
\end{tabular}

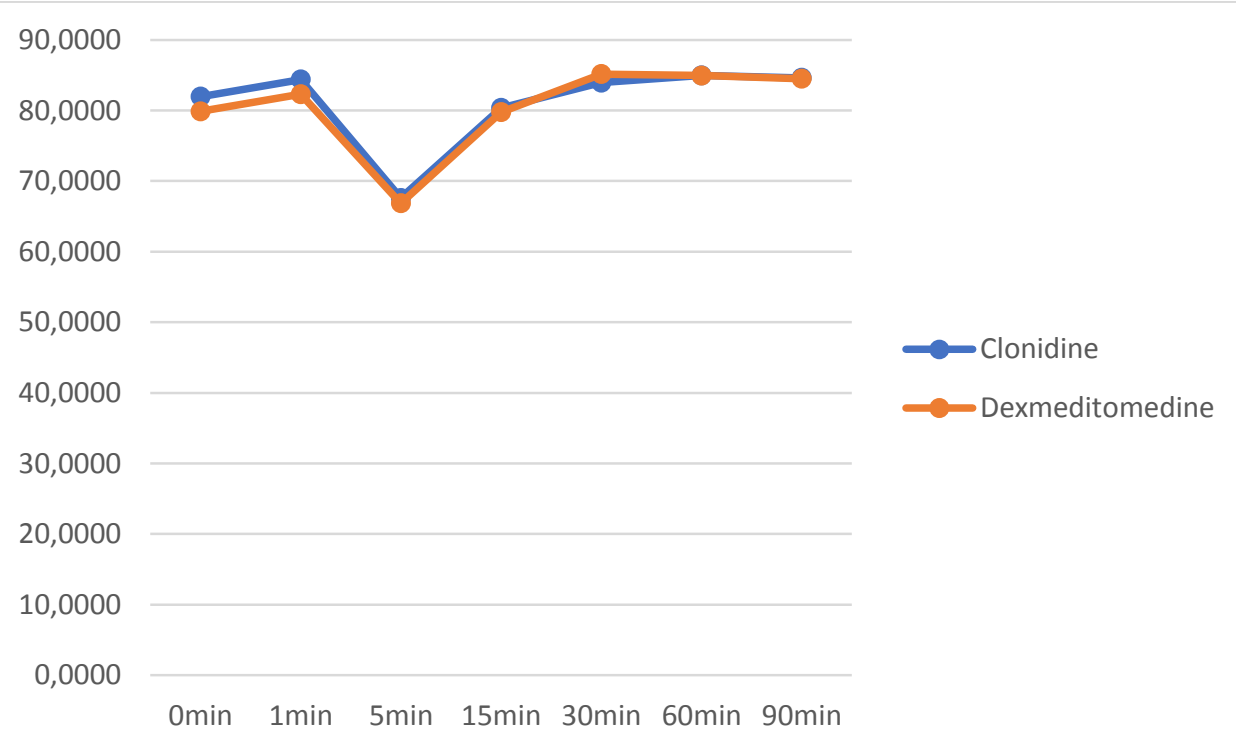


SPo2 during the procedure:

The mean Spo2 is steady throughout the procedure in both the groups.

\begin{tabular}{|c|c|c|c|c|c|}
\hline \multicolumn{6}{|l|}{ SPO2 } \\
\hline \multirow[b]{2}{*}{ Parameters } & \multicolumn{2}{|c|}{ Clonidine } & \multicolumn{2}{|c|}{ Dexmeditomedine } & \multirow[b]{2}{*}{$\mathrm{p}$ value } \\
\hline & Mean & Standard Deviation & Mean & Standard Deviation & \\
\hline $0 \mathrm{~min}$ & 98.9667 & 0.8899 & 98.9667 & 0.7649 & 1.0000 \\
\hline $1 \mathrm{~min}$ & 99.0333 & 0.8899 & 99.1000 & 0.8847 & 0.7721 \\
\hline $5 \mathrm{~min}$ & 99.2000 & 0.7611 & 98.9000 & 0.7589 & 0.1317 \\
\hline $15 \mathrm{~min}$ & 99.1333 & 0.8193 & 99.1000 & 0.8847 & 0.8802 \\
\hline $30 \mathrm{~min}$ & 99.3333 & 0.7581 & 99.1667 & 0.7915 & 0.4083 \\
\hline $60 \mathrm{~min}$ & 98.8333 & 0.8339 & 98.8667 & 0.7761 & 0.8732 \\
\hline $90 \mathrm{~min}$ & 98.9333 & 0.8683 & 99.3333 & 0.7112 & 0.0558 \\
\hline
\end{tabular}

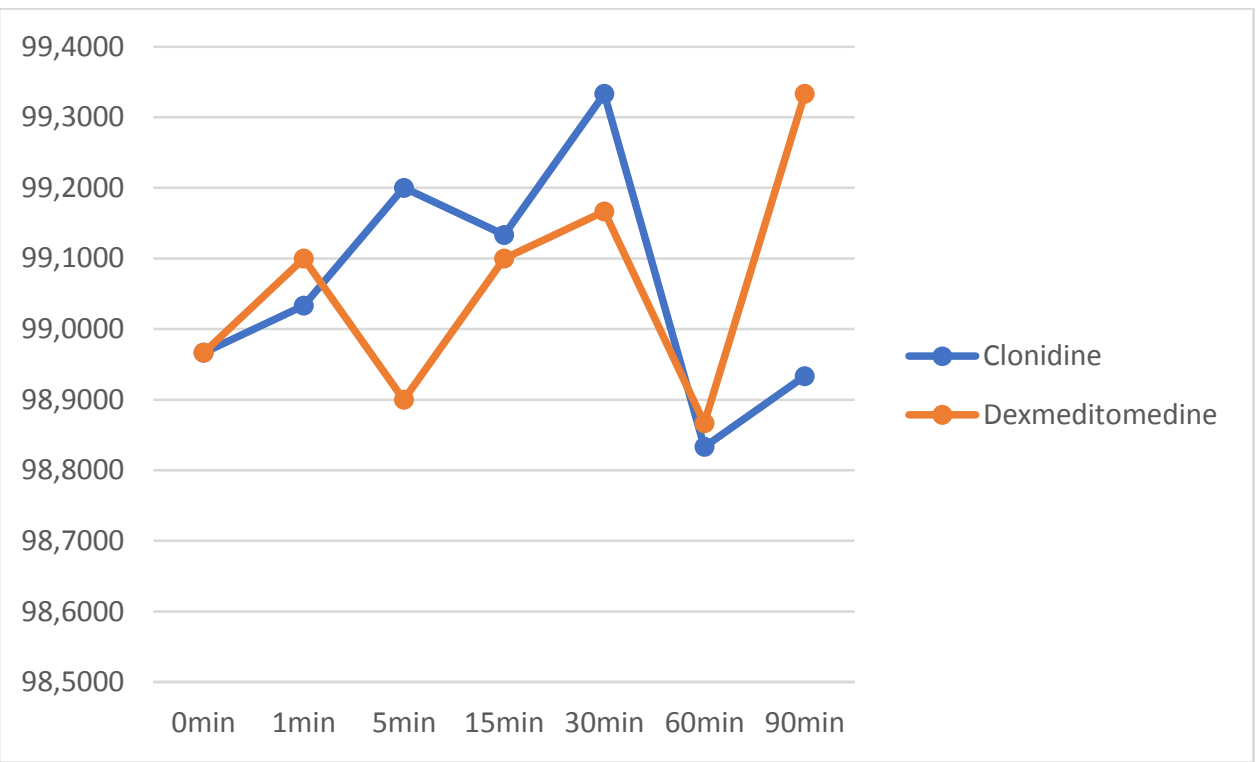

\section{Discussion}

Outcomes of this particular prospective, randomized, double blinded analysis show that inclusion of $1 \mu \mathrm{g} / \mathrm{kg}$ dexmedetomidine to $0.125 \%$ Levobupivacaine creates longer period of analgesia when compared with inclusion of $2 \mu \mathrm{g} / \mathrm{kg}$ weight of clonidine to $0.125 \%$ levobupivacaine epidurally for postoperative analgesia. Inclusion of dexmedetomidine to levobupivacaine likewise hastens the coming of analgesia and raises sedation score.

Control of postoperative pain constitutes a significant issue for doctors that take care of postoperative patients. Additionally, good control of postoperative pain is vitally important to reduce numerous pulmonary, metabolic, and mental complications. ${ }^{[9]}$ Many scientific studies have indicated the usage of postoperative epidural analgesia in complications are reduced by highrisk patients to a much better extent. ${ }^{[10]}$
Many scientific studies show that epidural analgesia with local anaesthetics coupled with opioid allows for far better postoperative analgesia compared to systemic opioid or epidural analgesia by itself which improves the surgical outcome. ${ }^{[11,12]}$ Nevertheless, the usage of neuraxial opioids was related to a number of side effects, therefore different choices like $\alpha 2$ agonists are being thoroughly examined as a substitute with focus on opioid related side effects such as for instance respiratory depression, urinary retention, nausea, then pruritus. ${ }^{[17]}$ The utilization of a2agonists for regional neural blockade in conjunction with local anaesthetic leads to improved duration of sensory blockade without any distinction in onset time.

Bupivacaine is popular medication within epidural anaesthesia, though numerous researches has recognized the severe negative effects serotonin and concern about therapy resistant aerobic 
toxicity with bupivacaine which resulted in the launch of the newer representative levobupivacaine ( $S$ enantiomer of bupivacaine). Levobupivacaine, a long acting enantiomerically fresh (S enantiomer) amide-type nearby anaesthetic, exerts the pharmacological action of its via reversible blockade of neuronal salt routes with a medical profile much like which of bupivacaine. ${ }^{[13]}$ Levobupivacaine with the safe pharmacological profile of its, minimal main nervous system as well as cardiac toxicity, differential neuraxial blockade with preservation of engine perform at concentrations that are low (0.125\%), compatibility with $\alpha 2$ agonists has become turning into a crucial choice for local anaesthesia and analgesia.

In the current study, the hypothesis is the fact that dexmedetomidine became a much better neuraxial adjuvant to levobupivacaine in comparison with clonidine for offering early onset and extended postoperative epidural analgesia and healthy cardiorespiratory parameters. ${ }^{[19]}$

A report by Saravana Babu et al. realized that epidural route offers appropriate analgesia in the postoperative period. ${ }^{[14]}$ Dexmedetomidine is a much better neuraxial adjuvant to ropivacaine in comparison with clonidine for offering early onset and stable cardiorespiratory parameters and prolonged postoperative analgesia. This particular analysis is in total agreement with the study of ours wherein beginning of analgesia (7.26 \pm 0.96 compared to $7.96 \pm 0.85$ ) was previously in Dexmed group. Duration of analgesia is extended with Dexmed group in comparison with clonidine group $(405.6 \pm 20.32$ vs. $347.9 \pm 15.05)$, with healthy cardiorespiratory parameters in dexmedetomidine team. Sedation was statistically and better significant in Dexmed group at thirty $\min (1.64 \pm 0.48$ vs. $1.36 \pm 0.48)$ as well as one $h$ $(2.18 \pm 0.38$ vs. $1.96 \pm 0.19)$ in comparison with clonidine group. ${ }^{[21]}$

Bajwa SJ et al. conducted a randomized and prospective research which included fifty adult female individuals between age of forty four as well as sixty five years of ASA bodily Classes I and II who underwent vaginal hysterectomies. ${ }^{[15]}$ Group RD got $17 \mathrm{ml}$ of $0.75 \%$ epidural ropivacaine along with $1.5 \mu \mathrm{g} / \mathrm{kg}$ of dexmedetomidine, while Group $\mathrm{RC}$ received admixture of seventeen $\mathrm{ml}$ of $0.75 \%$ ropivacaine as well as $2 \mu \mathrm{g} / \mathrm{kg}$ of clonidine. They found that inclusion of dexmedetomidine to ropivacaine led to earlier beginning of sensory analgesia at T10 as compared to inclusion of clonidine which is the same result we got in our group. ${ }^{[20]}$

Sedation score of dexmedetomidine was statistically and better substantial compared to that of clonidine; the mean time for 2 segment regression as well as motor blockade had been extended in dexmedetomidine team. ${ }^{[18]}$ Moreover, time for original recovery analgesia was substantially prolonged with dexmedetomidine class when as opposed with the clonidine group. They realized that dexmedetomidine is a much better adjuvant compared to clonidine wearing epidural anaesthesia as much as affected person comfort, healthy cardiorespiratory parameters, intraoperative, and postoperative analgesia are concerned. ${ }^{\text {[22] }}$

From the study of ours, dexmedetomidine is a much better neuraxial adjuvant compared to clonidine in supplying healthy hemodynamic parameters with much better \& statistically significant sedation amounts at thirty min as well as one $\mathrm{h}$ and extended postoperative analgesia $405.6 \pm 20.32$ vs. $347.9 \pm 15.05$ ).

Oriol-López and Maldonado-Sánchez conducted a prospective study in 40 patients who were subjected to abdominal surgery under epidural anaesthesia. ${ }^{[16]}$ They were given epidural dexmedetomidine at a dose of $1 \mu \mathrm{g} / \mathrm{kg}$ plus lidocaine and epinephrine at $3-4 \mathrm{mg} / \mathrm{kg}$. The obtained sedation amount, based on Ramsey, at five min was of three, and also it had been of 34 from fifteen to ninety $\mathrm{min}$, in ninety $\%$ of the public. They realized that ample sedation (Ramsay sedation level of $34, \mathrm{P}=0.05$ ) was maintained between ten along with $120 \mathrm{~min}$ thanks to one bolus epidural serving of dexmedetomidine. 


\section{Limitation}

Limitation of our study is that we had no placebo group and further scope will be to design the study with different doses of $\alpha 2$ agonists.

\section{Conclusion}

We finally determine and conclude that dexmedetomidine $1 \mu \mathrm{g} / \mathrm{kg}$ is a much better neuraxial adjuvant to levobupivacaine $0.125 \%$ in comparison with clonidine $2 \mu \mathrm{g} / \mathrm{kg}$ for offering early onset and extended postoperative epidural analgesia with healthy cardiorespiratory parameters for pelvis\& lower limb orthopaedic surgeries.

\section{References}

1. Rawal N, Schollin J, Wesström G. Epidural versus combined spinal epidural block for cesarean section. Acta Anaesthesiol Scand. 1988;32:61-6.

2. Yousef AA, Atef AM, Awais WM. Comparison of fentanyl versus meperidine as supplements to epidural clonidinebupivacaine in patients with lower limb orthopedic surgery under combined spinal epidural anesthesia. BMC Anesthesiol. 2015;15:146.

3. Tummala V, Rao LN, Vallury MK, Sanapala A. A comparative study-efficacy and safety of combined spinal epidural anesthesia versus spinal anesthesia in highrisk geriatric patients for surgeries around the hip joint.Anesth Essays Res. 2015;9:185-8.

4. Xiao F, Xu WP, Zhang YF, Liu L, Liu X, Wang LZ. The dose-response of intrathecalropivacaine co-administered with sufentanil for cesarean delivery under combined spinal-epidural anesthesia in patients with scarred uterus. Chin Med J (Engl) 2015;128:2577-82.

5. Sessler CN, Grap MJ, Ramsay MA. Evaluating and monitoring analgesia and sedation in the Intensive Care Unit. Crit Care. 2008;12(Suppl 3):S2.
6. Hjermstad MJ, Fayers PM, Haugen DF, Caraceni A, Hanks GW, Loge JH, et al. Studies comparing Numerical Rating Scales, Verbal Rating Scales, and Visual Analogue Scales for assessment of pain intensity in adults: A systematic literature review. J Pain Symptom Manage. 2011;41:1073-93.

7. Bajwa SJ, Kaur J. Clinical profile of levobupivacaine in regional anesthesia: A systematic review. J Anaesthesiol Clin Pharmacol. 2013;29:530-9.

8. Leone S, Di Cianni S, Casati A, Fanelli G. Pharmacology, toxicology, and clinical use of new long acting local anesthetics, ropivacaine and levobupivacaine. Acta Biomed. 2008;79:92-105.

9. Burlacu CL, Buggy DJ. Update on local anesthetics: Focus on levobupivacaine. Ther Clin Risk Manag. 2008;4:381-92.

10. Afonso J, Reis F. Dexmedetomidine: Current role in anesthesia and intensive care. Rev Bras Anestesiol. 2012;62:11833.

11. Bajwa SJ, Bajwa SK, Kaur J, Singh G, Arora V, Gupta S, et al. Dexmedetomidine and clonidine in epidural anaesthesia: A comparative evaluation. Indian J Anaesth. 2011;55:116-2

12. Liu N, Bonnet F, Delaunay L, Kermarec N, D'Honneur G. Partial reversal of the effects of extradural clonidine by oral yohimbine in postoperative patients. $\mathrm{Br} \mathbf{J}$ Anaesth. 1993;70:515-8.

13. MacDonald E, Kobilka BK, Scheinin M. Gene targeting - Homing in on alpha 2adrenoceptor-subtype function. Trends Pharmacol Sci. 1997;18:211-9.

14. Ruokonen E, Parviainen I, Jakob SM, Nunes S, Kaukonen M, Shepherd ST, et al. Dexmedetomidine versus propofol/ midazolam for long-term sedation during mechanical ventilation. Intensive Care Med. 2009;35:282-90.

15. Guinter JR, Kristeller JL. Prolonged 
infusions of dexmedetomidine in critically ill patients. Am J Health Syst Pharm. 2010;67:1246-53.

16. Gerlach AT, Murphy CV, Dasta JF. An updated focused review of dexmedetomidine in adults. Ann Pharmacother. 2009;43:2064-74.

17. Arunkumar S, Hemanth Kumar VR, Krishnaveni N, Ravishankar M, Jaya V, Aruloli M. Comparison of dexmedetomidine and clonidine as an adjuvant to ropivacaine for epidural anesthesia in lower abdominal and lower limb surgeries. Saudi J Anaesth. 2015;9:404-8.

18. Jain D, Khan RM, Kumar D, Kumar N. Perioperative effect of epidural dexmedetomidine with intrathecal bupivacaine on haemodynamic parameters and quality of analgesia. South Afr J AnaesthAnalg. 2012;18:105-9.

19. Fukushima K, Nishini Y, Mori K, Takeda J. Effect of epidurally administered dexmedetomidine on sympathetic activity and postoperative pain in man. Anesth Analg. 1996;82:S121.

20. Salgado PF, Sabbag AT, Silva PC, Brienze SL, Dalto HP, Módolo NS, et al. Synergistic effect between dexmedetomidine and $0.75 \%$ ropivacaine in epidural anesthesia. Rev Assoc Med Bras. 2008;54:110-5.

21. Ishii H, Kohno T, Yamakura T, Ikoma M, Baba H. Action of dexmedetomidine on the substantiagelatinosa neurons of the rat spinal cord. Eur J Neurosci. 2008;27: 3182-90.

22. Langer SZ, Duval N, Massingham R. Pharmacologic and therapeutic significance of alpha-adrenoceptor subtypes. J Cardiovasc Pharmacol. 1985;7 (Suppl 8):S1-8. 